\title{
Enhancing the antimalarial activity of artesunate
}

\section{J. O. Adebayo ${ }^{1}$ (I) - H. Tijjani $^{2}$ - A. P. Adegunloye ${ }^{1}$ - A. A. Ishola ${ }^{1}$ • E. A. Balogun ${ }^{1}$ - S. O. Malomo ${ }^{1}$}

Received: 30 January 2020 / Accepted: 25 June 2020 / Published online: 7 July 2020

(C) Springer-Verlag GmbH Germany, part of Springer Nature 2020

\begin{abstract}
The global challenge to the treatment of malaria is mainly the occurrence of resistance of malaria parasites to conventionally used antimalarials. Artesunate, a semisynthetic artemisinin compound, and other artemisinin derivatives are currently used in combination with selected active antimalarial drugs in order to prevent or delay the emergence of resistance to artemisinin derivatives. Several methods, such as preparation of hybrid compounds, combination therapy, chemical modification and the use of synthetic materials to enhance solubility and delivery of artesunate, have been employed over the years to improve the antimalarial activity of artesunate. Each of these methods has advantages it bestows on the efficacy of artesunate. This review discussed the various methods employed in enhancing the antimalarial activity of artesunate and delaying the emergence of resistance of parasite to it.
\end{abstract}

Keywords Artesunate $\cdot$ Combination therapy $\cdot$ Hybrids $\cdot$ Enhanced activity $\cdot$ Malaria

$\begin{array}{ll}\text { Abbreviations } & \\ \text { ACT } & \text { Artemisinin combination therapy } \\ \text { DHA } & \text { Dihydroartemisinin } \\ \text { DHFR } & \text { Dihydrofolate reductase } \\ \text { DIBAL } & \text { Diisobutylaluminium hydride } \\ \text { HP } \beta C D & \text { Hydroxypropyl } \beta \text { cyclodextrin } \\ \text { MCM } & \text { Mobil Composition of Matter } \\ \text { MEFAS } & \text { Mefloquine-artesunate hybrid } \\ \text { MRSA } & \text { Methicillin-resistant Staphylococcus aureus } \\ \text { oAMT } & \text { Oral artemisinin monotherapy } \\ \text { PABA } & \text { p-Aminobenzoic acid } \\ \text { PLGA } & \text { Polylactide-co-glycolide } \\ \text { PRIMAS } & \text { Primaquine-artesunate hybrid } \\ \text { RTS,S/AS01 } & \text { Mosquirix malaria vaccine } \\ \text { ZBS } & \text { Zinc basic salt } \\ \beta-C D & \beta \text {-Cyclodextrin }\end{array}$

Section Editor: Berit Bangoura

J. O. Adebayo

topebayo2002@yahoo.com

1 Department of Biochemistry, Faculty of Life Sciences, University of Ilorin, Ilorin, Nigeria

2 Department of Biochemistry, Bauchi State University, Gadau, Bauchi State, Nigeria

\section{Introduction}

Malaria is an infectious disease caused by the Plasmodium species, of which P. falciparum is the most virulent and is responsible for majority of the malaria morbidity and mortality recorded worldwide (Peter and Anatoli 1998). Other species of the genus Plasmodium that infect humans are $P$. vivax, P. knowlesi, P. ovale, and P. malariae. About 228 million cases of malaria were recorded globally in 2018 (World Health Organization 2019). This resulted in about 405,000 deaths, $94 \%$ of which occurred in the African region where the burden is highest (World Health Organization 2019). In addition to being a threat to human health, malaria is also a threat to the economy and development of sub-Saharan Africa (Sachs and Malaney 2002). The funding for malaria in 2018 was estimated at US $\$ 2.7$ billion (World Health Organization 2019), representing less than $41 \%$ of the total malaria funding of US $\$ 6.5$ billion required annually to meet the 2030 global malaria target (World Health Organization 2017). To eliminate malaria and its associated burden, some key approaches are employed: (i) the use of vector control and (ii) the use of antimalarial drugs for chemoprophylaxis or chemotherapy (Rappuoli and Aderem 2011). Hence, the target research areas include vector control, chemotherapy and vaccine development for the disease. However, resistance to insecticides and antimalarial drugs has hindered research breakthrough in vector control and chemotherapy respectively, while the most advanced malaria vaccine developed (RTS,S/AS01), for 
which the 3rd phase of clinical trial was completed in 2014 (Agnandji et al. 2015), is yet to guarantee up to 50\% protection and is best advised as a complementary malaria control tool rather than as a replacement package (World Health Organization 2020). The resistance developed to conventional antimalarial drugs, including the potent artemisinin derivatives, has led to the discouragement of monotherapy of such drugs. Thus, various efforts are being put in place globally to enhance the efficacy of artemisinin derivatives and delay the emergence of resistance to these drugs.

\section{Artemisinin}

Artemisinin (1) is a sesquiterpene lactone peroxide isolated from the leaves of the shrub Artemesia annua, better known indigenously as Qinghao in China (Mohammadi et al. 2020). Artemisinin is a 15-carbon compound with an endoperoxide bridge, which is crucial to its activity against Plasmodium species (Butler and Wu 1992). Artemisinin is effective against blood and early gametocyte stages of $P$. falciparum (Piyaphanee et al. 2006; White 2008). However, this effectiveness is endangered by the emergence of resistance of $P$. falciparum to artemisinin as reported in six countries/regions: Cambodia, Lao People's Democratic Republic, Myanmar, Thailand, Viet Nam, and the Myanmar-ChinaIndia border area (Noedl et al. 2008; Thu et al. 2017; Ouji et al. 2018). Likewise, parasite isolates from Nigeria and Madagascar have been reported to exhibit reduced sensitivity to artemisinin (Oduola et al. 1992; Randrianarivelojosia et al. 2001). Regions, such as western Cambodia, with the common use of artemisinin as monotherapy have shown resistance to artemisinin in clinical studies (White 2008). Decreased responses to treatments, specifically to artesunate and artemether, have also been reported in western Thailand (Luxemburger et al. 1998), India (Gogtay et al. 2000), and Sierra Leone (Sahr et al. 2001). Preserving the efficacies of artemisinin derivatives for the treatment of malaria is now the challenge.

\section{Improving the therapeutic efficacy of artemisinin}

Due to some challenges with the solubility and bioavailability of artemisinin, derivatives with different solubilities in oil and water have been synthesized. Some of these artemisinin derivatives are dihydroartemisinin (2), artemether (3), arteether (4), and artesunate (5) (Fig. 1). Artemether is oil-soluble and it is usually administered intramuscularly, while dihydroartemisinin and artesunate are water-soluble and are usually administered orally, except for severe malaria, which requires artesunate being administered via intravenous route. After administration, the artemisinins are rapidly absorbed, distributed and metabolized. Due to the emergence of resistance to oral artemisinin monotherapy (oAMT), it was replaced with artemisinin-based combination therapies (ACTs) (World Health Organization 2006, 2007), in which a fastacting artemisinin derivative is administered together with a slow-acting antimalarial drug of another class of antimalarials (Nigam et al. 2019; Mohammadi et al. 2020). ACTs are highly effective and efficacious globally and currently remain the recommended first-line treatment for uncomplicated malaria (World Health Organization 2010, 2015, 2019). The World Health Organization recommended the use of five different ACTs globally: artemether/ lumefantrine, artesunate/amodiaquine, artesunate/ sulfadoxine-pyrimethamine, artesunate/mefloquine, and dihydroartemisinin/piperaquine (World Health Organization 2017, 2019), while the sixth recommended ACT, artesunate/ pyronaridine (World Health Organization 2019), is used based on expression of resistance in regions. Close monitoring of resistance and necessary change of drug combinations due to change in response of infection to chemotherapy over time were also recommended (World Health Organization 2015). Also, in order to improve artemisinin activity, artemisinin dimers, trimers, and tetramers have been synthesized with each monomer retaining the peroxide bridge (Fröhlich et al. 2018). Artesunate, a water-soluble derivative, is administered as an oral drug, a rectal suppository and intravenous and intramuscular injections. Thus, it is more widely used compared to other derivatives. Improving its activity can enhance its effectiveness and delay the emergence of resistance to it. Therefore, this review deals with the different means and methods by which the therapeutic efficacy of artesunate has been improved through the years.

\section{Mechanisms of action of artemisinins}

Artemisinins are converted to active metabolite dihydroartemisinin, with the half-life of approximately $45 \mathrm{~min}$. By this, they are by far the most rapidly eliminated antimalarial drugs, with broad-stage specificity in action. Several mechanisms have been proposed for the antimalarial activities of artemisinins, including the generation of a carbon-centered radical (though now untenable), inhibition of polymerization of heme, production of free radicals and alteration of membrane transport properties of the malaria parasite, which inhibits the nutrient flow in the parasite (Eckstein-Ludwig et al. 2003; Krishna et al. 2004; Posner and O’Neill 2004; Drew et al. 2006, 2007; German and Aweeka 2008; Haynes et al. 2013).

\section{Inhibition of heme polymerization}

Artemisinins bind to heme through alkylation to form hemeartemisinin adduct (Krishna et al. 2004). This adduct binds to HRP II, a protein involved in the polymerization of heme (Lee 
Fig. 1 Artemisinin and its derivatives

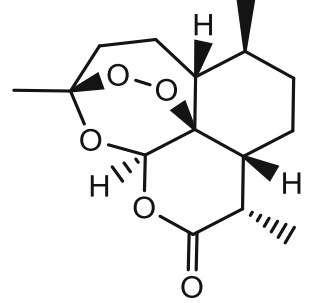

Artemisinin (1)

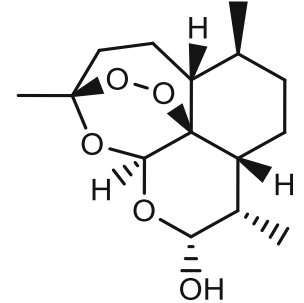

Dihydroartemisinin (2)

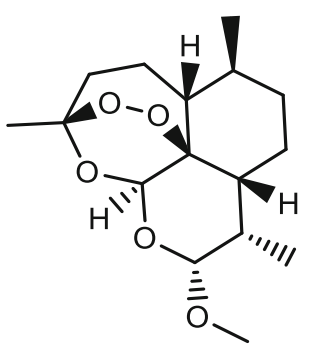

Artemether (3)<smiles>CCO[C@H]1O[C@@H]2OC3(C)CC[C@H]4[C@H](C)CC[C@H]([C@H]1C)[C@]42OO3</smiles>

Arteether (4)

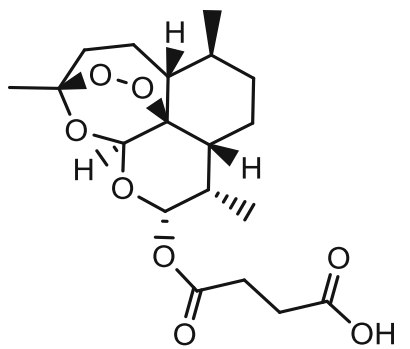

Artesunate (5) et al. 2019), thereby preventing hemozoin formation (Kannan et al. 2002). This leads to the accumulation of heme which is toxic to the parasite.

\section{Alkylation of protein}

Artemisinin has been reported to be involved in covalent interaction with $25 \mathrm{kDa}$ translationally controlled tumor protein (TCTP) homolog (Bhisutthibhan and Meshnick 2001). This protein has also been reported to perform a role in hemozoin formation. Artemisinin has also been reported to alkylate cysteine proteases, such as falcipain in P. falciparum (Pandey et al. 1999), thereby impairing its role in hemoglobin digestion. The alkylation of proteins by artemisinin is heme dependent.

\section{Inhibition of PfATP6}

Artemisinin has been reported to inhibit PfATP6, also known as sarco/endoplasmic reticulum Ca ATPase (SERCA) (Eckstein-Ludwig et al. 2003), thereby disturbing intracellular calcium homeostasis. It is found in the endoplasmic reticulum membrane where it functions in transporting $\mathrm{Ca}^{2+}$ ion from the cytoplasm into the endoplasmic reticulum, where it is stored.

\section{Generation of reactive oxygen species}

The mechanism of action of artemisinin has been linked with the generation of reactive oxygen species (ROS) such as hydroxyl, superoxide, alkoxyl, and peroxyl radicals. These are formed from Fenton reaction in $\mathrm{Fe}^{2+}$-dependent reaction. An increase in ROS leads to the depletion of antioxidant species in the parasite (Hunt and Stocker 1990). Initially, it was believed that the conversion of artemisinin to carbon-centered radical was crucial to the generation of ROS, but recently, that hypothesis has been reported to be untenable (Haynes et al. 2013).

\section{Destabilization of the parasite membrane}

Artemisinin has been reported to accumulate in neutral lipids, inducing oxidative damage. The inhibition of heme polymerization leads to the accumulation of heme which also induces ROS generation. The generation of ROS induces oxidative damage of the membrane (Haynes et al. 2013).

\section{Artesunate}

Artesunate (5), also known as dihydroartemisinin-12- $\alpha$-succinate, is a potent, semisynthetic antimalarial compound derived from its parent compound, artemisinin, in a two-step reaction involving reduction and esterification using diisobutylaluminum hydride (DIBAL) and succinic anhydride respectively (Chekem and Wierucki 2006). Artesunate has improved solubility, absorption and pharmacokinetics ( $\mathrm{Li}$ et al. 1998). This allows it to be recommended as an oral, 
rectal, intramuscular and intravenous medication for uncomplicated and severe malaria (Barnes et al. 2004; Harin et al. 2006).

Artesunate has a short half-life of between 20 and $45 \mathrm{~min}$ by oral route (OS) (Morris et al. 2011) and is metabolized through esterase-catalyzed hydrolysis within this short time to dihydroartemisinin, which is the active metabolite responsible for its antimalarial activity (Teja-Isavadharm et al. 2001; Gautam et al. 2009). Dihydroartemisinin is converted to its inactive form through glucuronidation via UDPglucuronosyl transferase (Ilett et al. 2002). A little amount of the DHA is also eliminated via the bile as glucuronides (TejaIsavadharm et al. 2001).

\section{Improving the antimalarial activity of artesunate}

Since the discovery of artesunate, several modifications have been done to this compound, in an attempt to improve its effectiveness and delay the emergence of resistance to it. The most widely accepted approach, as approved by the $\mathrm{WHO}$, is the combination of the fast-acting artesunate with another slow-acting drug, usually from another class of antimalarials. Other approaches to improve its activity are also well documented. These include the synthesis of hybrid compounds, the use of drug delivery systems, chemical modification, etc. (Fig. 2).
Approaches that yielded antimalarials in clinical use

The approaches discussed in this section include those that have yielded drugs that are currently undergoing clinical trials and those already in clinical use.

\section{Chemical modification}

Sodium artesunate Sodium artesunate (5a) is a basic salt as opposed to the acidic form and the recommended form for the treatment of uncomplicated and severe malaria due to its solubility (Fig. 3). It is a water-soluble compound which can be administered either as an intravenous or intramuscular drug (Batty et al. 1996). Sodium artesunate is more active in parasite clearance compared to quinine and some other antimalarials because of its fast action and better tolerance; however, it is less potent compared to its acidic form. Its activities against resistant malaria parasite strains are also well documented (Batty et al. 1996; White 1999a, b). The administration of sodium artesunate was reported to increase urinary excretion of sodium, chloride and potassium ions in Wistar rats (Campos et al. 2001). In addition, Campos et al. (2001) reported that administration of sodium artesunate led to an increase in the concentrations of metabolites of nitric oxide (nitrite and nitrates), which have been linked with protection against malaria (Taylor-Robinson and Looker 1998).
Fig. 2 Methods employed in improving the antimalarial activity of artesunate

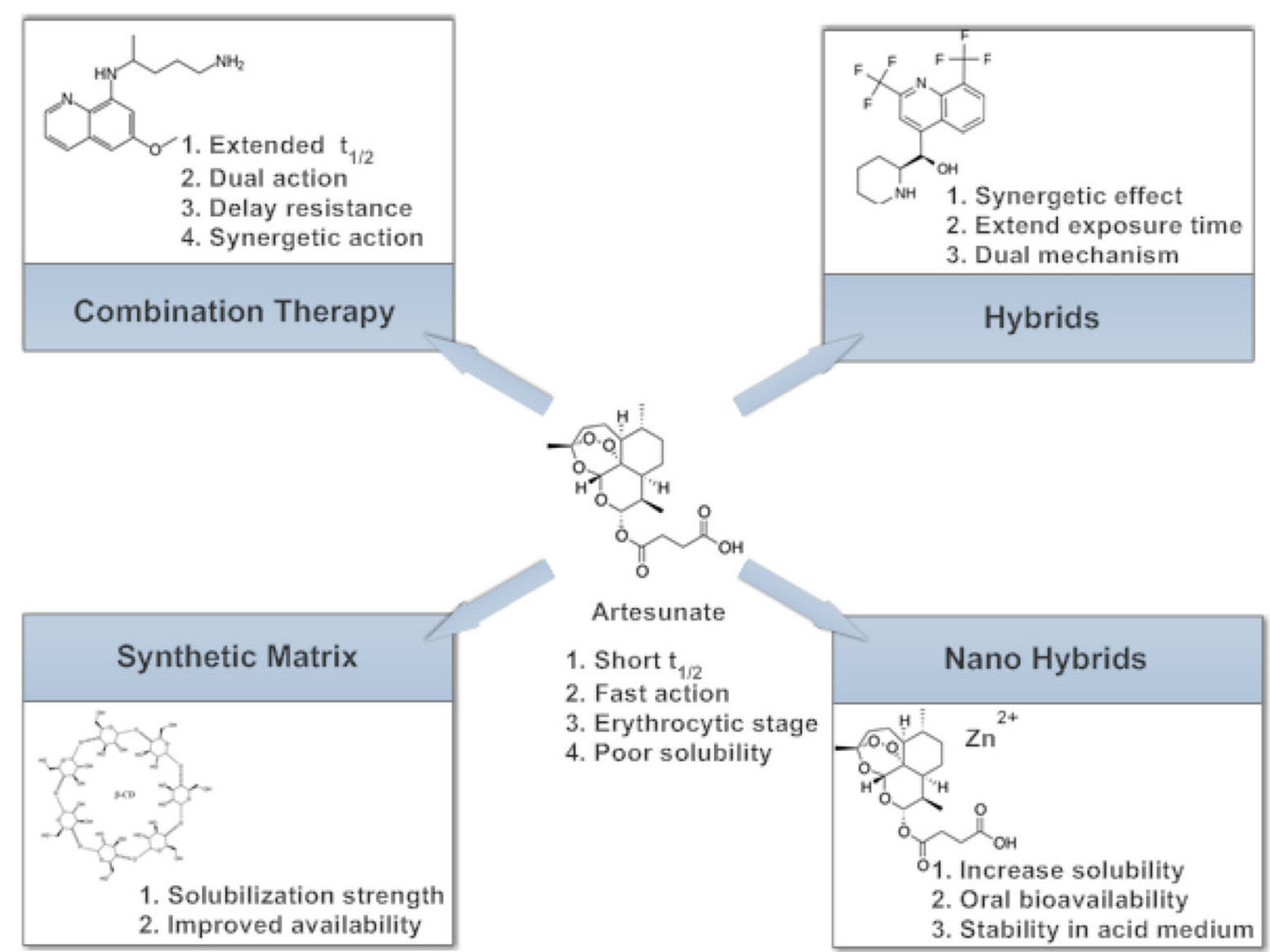




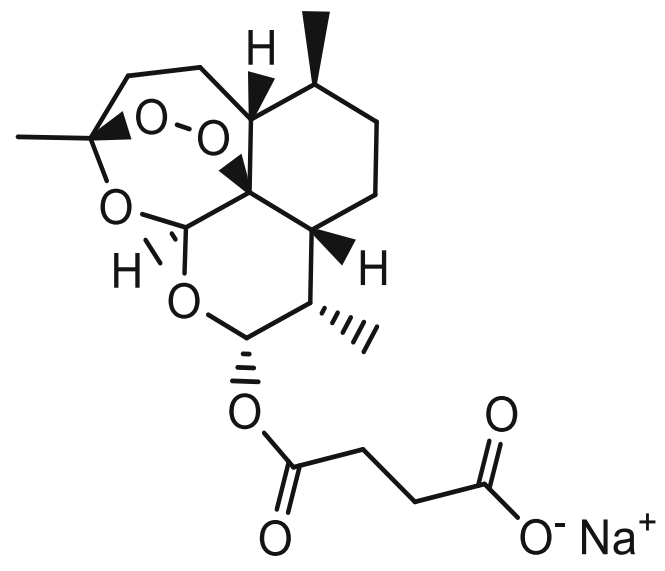

(5a)

Fig. 3 Chemical structure of sodium artesunate

\section{Combination therapy}

The resistance of malaria parasite to chloroquine in regions of Southeast Asia, South America and along the east coast of Africa led to the withdrawal of chloroquine as first-line treatment for uncomplicated $P$. falciparum malaria (World Health Organization 2001). Similarly, the use of artesunate monotherapy, as chloroquine replacement, could not be continued due to the emergence of parasite resistance to it (Sahr et al. 2001). This, therefore, led to the introduction of ACT (World Health Organization 2007). Different ACTs containing artesunate have been used since then with continued monitoring. ACTs are available as fixed dose combinations; the drug combinations are prepared in "ready to take formulation," also known as "co-blister." Unlike taking a series of drug regimens in multiple tablets, this ACT formulation approach improves patient's compliance during treatments (Lacaze et al. 2011). The choice of partner drugs for combination with artesunate is guided by the following principles: (i) the drug should act synergistically with artesunate (Majori 2004), (ii) it should be slow-acting, and (iii) it should exhibit a different mechanism of action in order to delay the emergence of drug resistance (White 1998). Studies have indicated that the inclusion of artesunate does not influence the pharmacokinetics of other components (van Vugt et al. 1999). When the sensitivity of a partner drug in the ACT decreases, such drug is replaced with another which possesses a higher sensitivity. Artesunatebased combination therapies containing primaquine, mefloquine, pyronaridine, amodiaquine, or piperaquine as partner drug have been formulated as single doses (Fig. 4). Also, artesunate is combined with chlorproguanil-dapsone, sulfadoxine-pyrimethamine, atovaquone-proguanil, and some antibiotics like clindamycin, tetracycline, and doxycycline (Fig. 5).

Primaquine-artesunate combination Primaquine (6) is an 8aminoquinoline, which has been in use since the 1950s. Primaquine is a hypnozoitocidal drug, which when given at the right dose, is also effective against asexual stages of P. vivax (Pukrittayakamee et al. 2000). Primaquine is still the only drug currently used worldwide for the treatment of relapses from $P$. vivax malaria due to dormant hypnozoites (Waters and Edstein 2012) and for the inhibition of formation of gametocytes of the parasite (Waters and Edstein 2012). Primaquine is generally absorbed but with short half-life of between 3.7 and $9.6 \mathrm{~h}$, though longer than that of artesunate (Edwards et al. 1993; Cuong et al. 2006). Its combination with artesunate is highly effective against the gametocyte of $P$. falciparum and equally effective as a hypnozoitocidal drug for the treatment of $P$. vivax and $P$. ovale infections (Baird and Hoffman 2004; Graves et al. 2012; World Health Organization 2012; Galappaththy et al. 2013).

Amodiaquine-artesunate combination Amodiaquine (7) belongs to the class 4-aminoquinoline (Teixeira et al. 2014) and is a derivative of quinoline, with modifications in its side chain. It has both schizonticidal and gametocytocidal activities against Plasmodium species. After an oral administration of amodiaquine, it is rapidly absorbed and metabolized to its active metabolite called desethylamodiaquine. Amodiaquine and desethylamodiaquine have longer half-lives $(5 \mathrm{~h}$ and above 6 days, respectively) (Krishna and White 1996) compared to artesunate. The combination of the two drugs is recommended for the treatment of uncomplicated falciparum malaria. This combination has been demonstrated to be more effective than amodiaquine monotherapy in African children by improving the cure rate and reducing gametocytemia (Adjuik et al. 2002).The mechanism of action of amodiaquine is still not completely understood. However, earlier reports have shown that amodiaquine inhibits the polymerization of heme to the insoluble product, hemozoin, in the parasite (Ginsburg et al. 1998).

Pyronaridine-artesunate combination Pyronaridine (8) is another drug used in combination with artesunate for the treatment of uncomplicated $P$. falciparum and $P$. vivax malaria (Poravuth et al. 2011; Rueangweerayut et al. 2012). Pyronaridine was synthesized in the 1970s, after the emergence of parasite resistance to chloroquine. It is a derivative of 10-phenyl aminobenzo[ $b][1,5]$ naphthyridine. The ratio of artesunate and pyronaridine in the combination is $1: 3$ respectively. Pyronaridine was reported to be active against erythrocytic stages of Plasmodium species in mouse models (Looareesuwan et al. 1996; Ye and Shao 1990). Also documented are the in vitro activities of pyronaridine against the 
Fig. 4 Chemical structures of some artesunate partner drugs<smiles>CC(C)NC(=N)NC(=N)Nc1ccc(Cl)cc1</smiles>

Proguanil (12)<smiles>CCN(CC)Cc1cc(Nc2ccnc3cc(Cl)ccc23)ccc1O</smiles>

Amodiaquine (7)<smiles>COc1ccc2nc3cc(Cl)ccc3c(Nc3cc(CN4CCCC4)c(O)c(CN4CCCC4)c3)c2c1</smiles>

Pyronaridine (8)<smiles>OC(c1cc(C(F)(F)F)nc2c(C(F)(F)F)cccc12)C1CCCCN1</smiles>

Mefloquine (9)<smiles>COc1ncnc(NS(=O)(=O)c2ccc(N)cc2)c1OC</smiles>

Sulfadoxine (10)<smiles>CCc1nc(N)nc(N)c1-c1ccc(Cl)cc1</smiles>

Pyrimethamine (11)
$\mathrm{Cl}$<smiles>Cc1ccc(N2C(N)=NC(N)=NC2(C)C)cc1</smiles>

cycloguanil (13)<smiles>O=C1c2ccccc2C(=O)C(C2CCC(c3ccc(Cl)cc3)CC2)C1O</smiles>

Atovaquone (14)<smiles>Nc1ccc(S(=O)(=O)c2ccc(N)cc2)cc1</smiles>

Dapsone (15)<smiles>CCC[C@@H]1CC(C(=O)NC(C(C)Cl)C2OC(SC)C(O)C(O)C2O)N(C)C1</smiles>

Clindamycin (18)

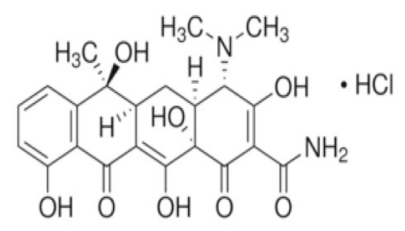

Tetracycline (19)<smiles>C[C@@H]1[C@H]2C(=C(O)[C@]3(O)C(=O)C(C(N)=O)=C(O)[C@@H](N(C)C)[C@H]3[C@@H]2O)C(=O)c2c(O)cccc2[C@@H]1C</smiles>

Doxycycline (20)

Fig. 5 Some antibiotics co-administered as antimalarial<smiles>CC(C)N=C(N)/N=C(\N)Nc1ccc(Cl)c(Cl)c1</smiles>

Chlorproguanil (16)<smiles>CN(C)CC1CC2CCC(C2)C1CNc1ccnc2cc(Cl)ccc12</smiles>

Ferroquine (17)

multidrug-resistant $P$. falciparum isolates (Institute of Parasitic Diseases Chinese Academy of Medical Sciences 1980). Resistance to pyronaridine has been observed in some Plasmodium strains (Wu 1988; Li et al. 1995). The mechanism of action of pyronaridine involves the inhibition of $\beta$ hematin formation, resulting in the death of the parasite. It also involves the formation of a drug-hematin complex. This allows pyronaridine to inhibit the glutathione-dependent degradation of hematin and enhance hematin-induced lysis of red blood cell. Pyronaridine is active against all the asexual stages of $P$. falciparum, with higher potency than chloroquine (Croft et al. 2012).

Mefloquine-artesunate combination Mefloquine (9) was developed in the USA by the United States Army. Mefloquine is recommended for chemoprophylactic treatment of the infections of all Plasmodium species. Mefloquine was initially used 
in combination with sulfadoxine/pyrimethamine, to successfully treat resistant $P$. falciparum malaria (Nosten et al. 1987), until resistance emerged some years later (Nosten et al. 1991). The new formulation of artesunate-mefloquine was suggested by the WHO technical consultation team on antimalarial drug combination therapy in 2001 (World Health Organization 2001). The fixed dose of artesunate-mefloquine was recommended for daily use over a period of 3 days (ter Kuile et al. 1995; World Health Organization 2001). Mefloquine has a half-life of about 2 weeks and rapid asexual blood-stage and gametocyte clearance rate (White 1998). Mefloquine acts as an active schizonticidal drug but not as an effective gametocytocidal drug. Though its exact mechanism of action is not clear, it has high affinity for erythrocyte membrane and seems to act by inhibiting heme polymerization in malaria parasite (Palmer et al. 1993; Nosten et al. 2012; World Health Organization 2015).

\section{Sulfadoxine-pyrimethamine-artesunate combination} Sulfadoxine (10) has a structure which is similar to $p$ aminobenzoic acid (PABA), which serves as the basis for its use as an antifolate. Sulfadoxine blocks the production of dihydrofolic acid, which is essential for the biosynthesis of nucleic acid, by inhibiting the key enzyme dihydropteroate synthase (Nzila 2012). The combination of artesunate with sulfadoxine-pyrimethamine (SP) is among the antimalarial drugs strongly recommended by the WHO for the treatment of uncomplicated malaria in children and adult, except in the first trimester of pregnancy (World Health Organization 2015), which has been adopted in different countries with no adverse drug reactions (Obonyo et al. 2003; Marquiño et al. 2005). Sulfadoxine/pyrimethamine (11) combination with mefloquine was previously used for the treatment of resistant $P$. falciparum malaria before the development of resistance to this combination (Nosten et al. 1987; Nosten et al. 1991). Sulfadoxine-pyrimethamine-artesunate combination ensured a rapid decrease in fever and asexual parasite density; gametocytemia was also significantly lowered by the combination therapy compared to sulfadoxine-pyrimethamine treatment alone (Obonyo et al. 2003; Marquiño et al. 2005).

\section{Atovaquone-proguanil-artesunate combination}

Proguanil (12) is a prodrug, which is metabolized to cycloguanil (13). Proguanil is a strong schizonticidal drug and acts on asexual forms of the parasite. Proguanil inhibits dihydrofolate reductase (DHFR) activity of the parasite, thereby suppressing the reduction of dihydrofolate to tetrahydrofolate, which is necessary for the biosynthesis of amino acids and nucleic acids (Nzila 2012). Atovaquone (14), on the other hand, interferes with the integrity of parasite mitochondria and depolarizes its electron transport, thereby blocking parasite cellular respiration. In various clinical trials conducted, artesunate-atovaquone-proguanil combination was highly effective and well tolerated in the treatment of multidrugresistant $P$. falciparum malaria (van Vugt et al. 1999, 2002; Tahar et al. 2014; Wojnarski et al. 2019; Clinicaltrials.gov/ct2/ show/NCT02297477). In the right combination as a single formulated drug, it provides alternative treatment for pregnant women infected with multidrug-resistant $P$. falciparum (McGready et al. 2003). Although it may be expensive in its formulation, it provides an effective 3-day treatment for pregnant women (McGready et al. 2003). In a preclinical study, the use of nanosuspension of atovaquone in triple combination, in order to reduce the high cost and dose of atovaquone, has been reported to be effective, increasing its bioavailability two-fold (Harsha et al. 2020).

\section{Chlorproguanil-dapsone-artesunate combination} Artesunate, dapsone (15), and chlorproguanil (16) were developed as an affordable, fixed dose ACT for use in tackling the emergence of resistance of parasites to chlorproguanildapsone combination in Africa. They are metabolized after oral administration into the active metabolites dihydroartemisinin, monoacetyl dapsone and chlorcycloguanil, respectively. The latter provides a longer half-life to the ACT (Zuidema et al. 1986; Edstein and Veenendaal 1987). This antifolate combination is similar to SP, but with a rapid elimination from the body (Winstanley et al. 1997). This triple combination therapy has undergone phase III clinical trial (ClinicalTrials.gov Identifier: NCT00344006).

\section{Artesunate-lumefantrine-amodiaquine combination} Artesunate-lumefantrine-amodiaquine is another triple combination that is currently undergoing phase III clinical trial (Thu et al. 2017). Actually, the rationale for this triple combination therapy is to circumvent the limitations of the double combination therapy such as the emergence of resistance and high doses of partner drugs. This drug was effective when administered as a 3-day regimen (ClinicalTrials.gov Identifier: NCT02453308).

Combination with antibiotics Antibiotics are used for the prevention and treatment of diseases arising from microbial infection. Just like the malaria parasite, bacterial infection does not only pose health challenges but also economic burden due to the development of resistance by bacteria to conventional drugs (Gandra et al. 2014). The combination of an antibiotic with an antimalarial, if effective and safe, has been recommended for malaria endemic regions (White and Olliaro 1996; World Health Organization 2015). Clindamycin (18), tetracycline (19), and doxycycline (20) have been used specifically in combination with artesunate for the treatment of malaria (Fig. 4). 
Clindamycin is an effective antibacterial compound used for the treatment of pneumonia, inflammatory diseases and endocarditis. It is also active against methicillin-resistant Staphylococcus aureus (MRSA) (Daum 2007). Clindamycin is well tolerated when used for the treatment of $P$. falciparum malaria. Quinine/clindamycin combination is particularly recommended for children and is the drug of choice for pregnant women (Lell and Kremsner 2002; Griffith et al. 2007). Clindamycin is not recommended for use as an antimalarial monotherapy because isolates of $P$. falciparum have exhibited resistance to it (Dharia et al. 2010). However, it is used effectively in combination therapy because of its slow action when administered with a fast-acting drug, such as artesunate (Lell and Kremsner 2002; Griffith et al. 2007). Similarly, doxycycline is used to treat infection caused by protozoans or bacteria. It is recommended as a prophylactic drug, co-administered with quinine or artesunate as follow-up treatment for severe malaria or in combination with other antimalarials for uncomplicated malaria (World Health Organization 2015). Doxycycline is a preferred partner drug due to its longer half-life, reliable absorption and its renal safety profile (World Health Organization 2015). It acts by impairing Plasmodium asexual development (Pukrittayakamee et al. 2008). Also, its use is associated with increase in gametocytes and clearance time as recorded for sulfadoxine-pyrimethamine combination (Pukrittayakamee et al. 2008). Doxycycline is used to prevent malaria but it is not recommended for the initial treatment of malaria, even when the parasite is sensitive to it, since its antimalarial action is delayed (Dahl et al. 2006).

Combination of clindamycin with artesunate or quinine has been recommended for the treatment of severe or uncomplicated malaria in patients, including women in the second trimester of pregnancy; its administration is for 7 days (World Health Organization 2010). The mechanism of action involves the inhibition of microbial protein synthesis by binding to the 50S ribosomal subunit and interfering with peptide chain initiation (Tenson et al. 2003; World Health Organization 2010).

\section{Approaches that have yielded promising antimalarials at preclinical stage}

\section{Combination therapy}

Ferroquine-artesunate combination Ferroquine (17) is a 4aminoquinoline derivative of chloroquine with ferrocenic attached to its side chain. Ferroquines are the most potent of the chloroquine derivatives with antimalarial properties. Ferroquine and its derivatives, such as hydroxyferroquines, trioxaferroquines and chloroquine-bridged ferrocenophanes, have been extensively studied due to their promising antimalarial properties (Wani et al. 2015). They are used in combination with artesunate to ensure better activities and delay in the emergence of resistance to both compounds. Ferroquine alone is effective against the chloroquineresistant strain of P. falciparum (Biot 2004). It is believed to act by inhibiting hemozoin formation in the parasite (Biot et al. 2005).

\section{Synthesis of hybrids}

Hybrids are chemical compounds with two or more different structures and biological functions (Meunier 2007). Hybrid molecules are synthesized in order to bring a new pharmacophore, which is expected to bring a new property to the hybrid. Hybrid molecules with higher antimalarial activity or with a synergistic effect are reported to be good candidates for new antimalarial development.

Mefloquine-artesunate hybrid Mefloquine and artesunate have been used in combination therapy since 2001 (World Health Organization 2001), as well as with sulfadoxine/ pyrimethamine for the treatment of $P$. falciparum malaria (Nosten et al. 1987). The choice of artesunate and mefloquine as ACT partners is ideal because fast-acting and slow-acting drugs are combined (Wiseman et al. 2006). The quinolinic ring of mefloquine and the endoperoxide ring of artesunate were combined in a new hybrid molecule MEFAS (Varotti et al. 2008). MEFAS (21) had new features different from the parent compounds and was more potent than the parent compounds when administered alone and in different mass proportions (Fig. 6). The hybrid compound was effective against both chloroquine-sensitive (3D7, $\mathrm{IC}_{50} 1.1 \mathrm{ng} / \mathrm{ml}$ ) and chloroquine-resistant (W2, $\mathrm{IC}_{50} 1.0 \mathrm{ng} / \mathrm{ml}$ ) strains of P. falciparum parasites (Table 1). MEFAS was active in vivo against $P$. berghei, with no recrudescence during the 30 days of parasite monitoring (Varotti et al. 2008). MEFAS did not have SERCA as its target but altered the $\mathrm{pH}$ gradient across the parasite's digestive vacuole (Varotti et al. 2008).

Primaquine-artesunate hybrid Primaquine and artesunate (PRIMAS) is a hybrid molecule prepared from primaquine and artesunate in a similar manner to MEFAS. It is also a hybrid salt between the two parent compounds. The hybrid compound was designed to minimize the toxicity associated with primaquine (Boechat et al. 2014). Studies on PRIMAS (22) showed that it was a potent drug with less toxicity compared to the parent compound, primaquine. Also, results of in vitro and in vivo experiments revealed it to be more active against drug-resistant isolates compared to the parent compounds (Boechat et al. 2014).

Indoloquinoline-artesunate hybrid Indoloquinolines are isolates from the root of the medicinal plant Cryptolepis sanguinolenta, which is a climbing shrub. The isolated phytochemicals, cryptolepine, isocryptolepine, and 
Fig. 6 Artesunate hybrid compounds

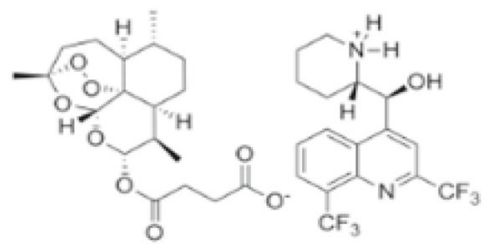

(21)

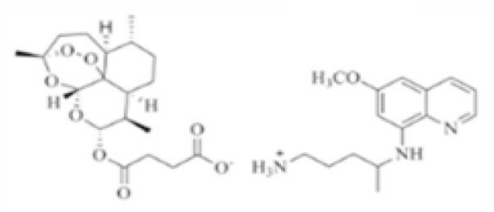

(22)

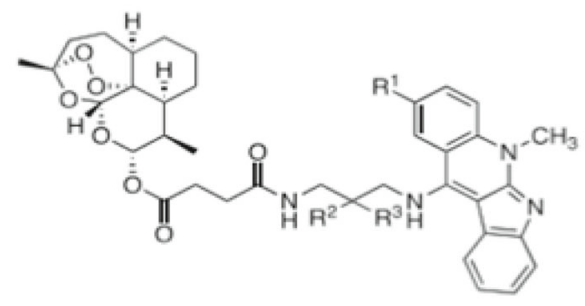

(23)

neocryptolepine, are promising antimalarial compounds (Kirby et al. 1995; Cimanga et al. 1997; Paulo et al. 2000). Wang et al. (2014) synthesized a series of indoloquinoline hybrids (artesunate-indolo[2,3- $b$ ]quinoline, artesunateindolo[3,2-c]quinoline and artesunate-indolo[3,2-b]quinolone) and evaluated their antimalarial properties. Indoloquinoline was linked to artesunate through the substitution of 3-aminopropylamino group of indoloquinolines with artesunate moiety to form an amide bond. The hybrid (23) expressed low cytotoxicity and increased antimalarial activity. They were active against chloroquine-sensitive (NF54) and chloroquine-resistant (K1) strains of $P$. falciparum with $\mathrm{IC}_{50}$ values of $0.45 \mathrm{nM}$ and $0.42 \mathrm{nM}$ respectively. The in vivo studies revealed that the hybrids had good antiplasmodial activities, reducing parasitemia by $89.6 \%$ on the 4 th day and expressing a mean survival time of 7.7 days (Wang et al. 2014). This hybrid molecule was a more potent inhibitor of $\beta$-hematin formation compared to its parent compounds, indicating it as one of its mechanisms of action.

Polyphenol-artesunate hybrids Recently, we synthesized antimalarial hybrid compounds from artesunate and some polyphenols present in Cocos nucifera husk, the decoction of which is used for the treatment of malaria in indigenous medicine in Nigeria (Adebayo et al. 2012, 2013). The compounds synthesized were artesunate-ellagic acid and artesunateprocyanidin hybrid compounds with a ratio of 1:1 of the components in each hybrid compound (Adebayo et al., unpublished; Balogun et al., unpublished). The artesunate-ellagic acid hybrid compound was found to be more active than artesunate against $P$. falciparum $\mathrm{W} 2$ in vitro, while artesunate-procyanidin hybrid compound was more active against $P$. berghei NK65 compared to artesunate in vivo (Adebayo et al., unpublished; Balogun et al., unpublished).
Table $1 \mathrm{IC}_{50}$ values for artesunate hybrid compounds

\begin{tabular}{|c|c|c|c|c|}
\hline $\begin{array}{l}\text { S/ } \\
\text { no. }\end{array}$ & Drug/hybrid & \multicolumn{2}{|c|}{$\mathrm{IC}_{50}$ (parasite strain) } & Reference \\
\hline 1. & Artesunate & $6.3 \mathrm{nM}(\mathrm{D} 10)$ & $31.2 \mathrm{nM}(\mathrm{Dd} 2)$ & Singh et al. (2014) \\
\hline 2. & Chloroquine & $21.8 \mathrm{nM}(\mathrm{D} 10)$ & $140 \mathrm{nM}(\mathrm{Dd} 2)$ & Singh et al. (2014) \\
\hline 3. & Mefloquine/artesunate & $1.1 \mathrm{ng} / \mathrm{ml}(3 \mathrm{D} 7)$ & $1.0 \mathrm{ng} / \mathrm{ml}(\mathrm{W} 2)$ & Varotti et al. (2008) \\
\hline 4. & Primaquine/artesunate & & $4.07 \mathrm{ng} / \mathrm{ml}(\mathrm{W} 2)$ & Boechat et al. (2014) \\
\hline 5. & Indoloquinoline/artesunate & 0.45 nM (NF54) & $0.42 \mathrm{nM}(\mathrm{K} 1)$ & Wang et al. (2014) \\
\hline
\end{tabular}

CQ-sensitive P. falciparum strains: D10, 3D7, and NF54; CQ-resistant strains: Dd2, W2, and K1 


\section{Use of drug delivery systems}

Nanohybrids have been used as drug delivery systems to release drugs into a particular site in the body at a specific rate. Different drug delivery systems have been developed, including liposomes, lipid nanoemulsions and polylactide-coglycolide (PLGA) and the use of natural polymers such as collagen and chitosan (Al-Qaraghuli et al. 2017; Obeid et al. 2017a, b).

Various strategies utilize liposomes and pheroids to improve the solubility and transport of antimalarial drugs to their target sites. Pheroids are biocompatible, biodegradable, and safe compounds used in medical applications. The poor solubility and erratic absorption of artemisone (25) following oral administration have been improved by using pheroids (Steyn et al. 2011). The formulation consisted of ethyl ester, cremaphor, $\alpha$-tocopherol, and butylated hydroxyanisole as oil phase, with nitrous oxide water as the water phase; the final pheroids obtained were $3.81 \mu \mathrm{m}$ in size (Steyn et al. 2011).

Liposomes were among the first drug delivery systems applied in disease therapy (Gregoriadis 1976). They are made up of phospholipid bilayers surrounded by central aqueous phase and are self-assembling spherical colloidal entities. They are amphiphilic, shielding hydrophobic groups from aqueous environment while maintaining contact with aqueous phase through their hydrophilic head groups (Makino and Shibata 2006). Liposomes have been used to encapsulate several antimalarial compounds, including artesunate, in order to improve their delivery to target organs. Gabriëls and PlaizierVercammen (2003) developed a liposome formulation to improve patient's compliance to the use of artesunate. To achieve this, liposome consisting of 4:3 molar ratio of phosphatidylcholine/cholesterol was used to develop a drug delivery system that ensured the slow release of artesunate.

Kim et al. (2015) prepared artesunate nanohybrids by intercalating it in zinc salt in an attempt to increase its solubility and oral bioavailability and prevent its degradation in acidic medium. Kim et al. (2015) also encapsulated the artesunatezinc basic salt (ZBS) in an enteric coating agent to further decrease the release of artesunate and prevent its decomposition at intestinal $\mathrm{pH}$. The synthesized nanohybrid significantly improved the aqueous solubility and chemical stability of artesunate in acidic conditions.

Recently, we also reported the use of mesoporous silica nanocarriers as effective drug delivery systems for artesunate and quinine (Amolegbe et al. 2018). Mobil Composition of Matter (MCM)-41 was found to be the most effective in delivering artesunate and quinine to the target site, the red blood cells, compared to other delivery systems. However, it was more effective in delivering quinine than artesunate. The MCM-41 nanoparticle delivery system for quinine enhanced the antimalarial activity of quinine by about 240 -fold, with
$0.0625 \mathrm{mg} / \mathrm{kg}$ body weight of quinine encapsulated in MCM-41 nanoparticle exhibiting higher inhibition of parasite growth compared to $15 \mathrm{mg} / \mathrm{kg}$ body weight of quinine (Amolegbe et al. 2018).

\section{Use of synthetic matrix}

Drug solubility is very important for delivery to target sites. Drug candidates from biological base screening or combination chemistry are mostly lipophilic and are expected to exert their therapeutic action across biological membranes or membrane-associated proteins (Fahr and Liu 2007).

Artesunate is a potent blood schizonticidal drug, the solubility of which has been described as poor. Its bioavailability is also low when administered through the oral route ( $\mathrm{Li}$ et al. 1998). These properties limit the therapeutic applications of artesunate (Zhang et al. 2009). Thus, improving its solubility could increase its delivery and therapeutic effects. Carbohydrate and noncarbohydrate matrices are employed to increase the solubility of drugs and enhance their delivery to target sites (Fahr and Liu 2007; Douroumis and Fahr 2013). This process transforms hydrophobic drugs to more watersoluble forms, thereby improving their delivery. Chadha et al. (2011) investigated the inclusion of artesunate in a carbohydrate matrix. $\beta$-Cyclodextrin $(\beta-\mathrm{CD})$ along with other matrix was prepared and evaluated for their physicochemical properties and therapeutic indices. Similarly, Muder and Sunderland (2014) investigated the inclusion of artesunate in hydroxypropyl $\beta$ cyclodextrin (HP $\beta C D$ ), which is a chemically modified $\beta-C D$ with some hydroxyl groups substituted with hydroxypropyl groups. The artesunate-cyclodextrin molecules increased the solubilization strength of artesunate, which was highest in methyl- $\beta$-cyclodextrin $(\mathrm{Me}-\beta-\mathrm{CD})$ (Chadha et al. 2011). More so, the binary Me- $\beta$-CD-lyophilized suspensions were effective against $P$. berghei infection in mice with no mortality recorded throughout the duration of the study (Chadha et al. 2011).

\section{Synthesis of co-crystals}

Synthesis of co-crystals of artesunate and nicotinamide using two separate methods of solvent evaporation and slurry increased the solubility and dissolution rate of artesunate but caused no significant increase in the in vivo antimalarial activity of artesunate alone (Setyawan et al. 2015). Co-crystal formation has been used to design crystals with improved properties such as solubility, bioavailability and stability, amidst other properties without altering the effectiveness of the parent compound (Chadha et al. 2012). The effect of nicotinamide in the crystal formed with artesunate seems to improve the dissolution of artesunate in water, but not its antiparasitic activities in vivo (Setyawan et al. 2015). 


\section{Chemical modifications}

Artemisone Artemisone (25), a polar heterocyclic compound, was synthesized from artesunate as a second-generation drug (Fig. 7). The modification conferred on artemisone improved pharmacokinetics and prolonged half-life and also alleviated the neurotoxicity associated with artesunate (Haynes 2006). Also, artemisone has been reported to be active against earlystage gametocytes and asexual stages (Coertzen et al. 2018). Its mechanism of action has been shown to include the inhibition of PfATPase6. It was also more efficient in killing malaria parasite than artesunate in animal studies. Further studies are still being carried out on the development of artemisone (Anthony et al. 2012; Schrader et al. 2012; Barnett and Guy 2014). Artemisone has undergone phase II clinical trial (Held et al. 2015).

Artesunate-polyamines The synthesis of polyamines of artesunate (26) and the evaluation of their activities against NF54 and K1 strains of P. falciparum were done by Pearce et al. (2017). Among the active artesunate-polyamine compounds are (Bis)-Boc-(bis)-artesunate-polyamine and (tetra)-

Fig. 7 Chemical structures of modified artesunate compounds

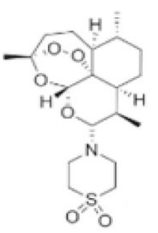

(25)

artesunate-polyamine conjugates which were active in vitro against the two strains with $\mathrm{IC}_{50}$ values ranging from 0.3 to $1.1 \mathrm{nM}$. These polyamine conjugates also caused $95.5-99.8 \%$ reduction in parasitemia with no death recorded for two of them in experimental animal studies after a 30-day monitoring period (Pearce et al. 2017).

\section{Artesunate dimers, trimers, and tetramers}

The peroxide bridge of artesunate is critical to its activity. Thus, hybrid compounds were synthesized from two or more compounds such that each monomer had an endoperoxide bridge and they were evaluated for their activities, relative to the monomers. Chaturvedi (2011) synthesized trimer and tetramer derivatives of artesunate (27), with some of the oligomers exhibiting good in vitro activities against chloroquinesensitive parasites. Some dimers were also synthesized and one of them had similar in vitro activity $\left(\mathrm{IC}_{50}=\right.$ $0.00077 \mu \mathrm{M})$ against chloroquine-sensitive Plasmodium species compared to artesunate (Paik et al. 2006). Artesunate trioxane dimer (28) prepared by Conyers et al. (2015) gave promising results in an animal model of malaria (Fig. 7). The

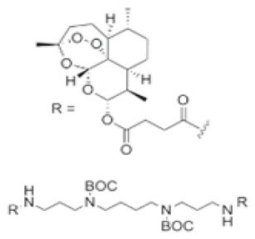

(26)

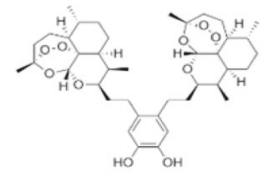

(27)

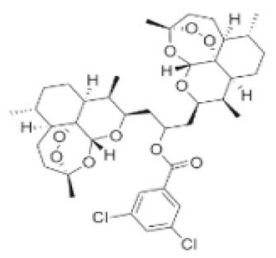

(28)
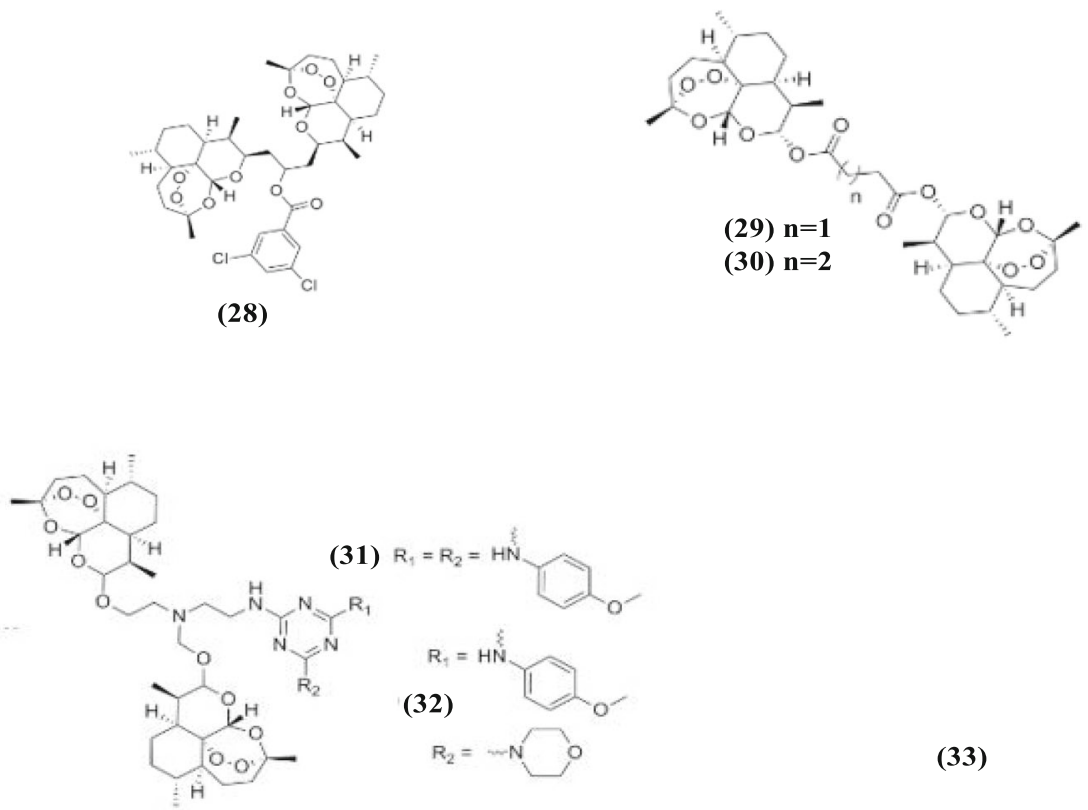
trioxane dimer was the most effective among the drugs tested, exhibiting complete parasite clearance and also extending the mean survival time of tested mice beyond 30 days. Reiter et al. (2015) prepared several artesunate dimers and trimers and evaluated their activities against $P$. falciparum $3 \mathrm{~d} 7$. The dimeric derivatives of artesunate ( $\mathbf{2 9}$ and $\mathbf{3 0}$ ) were more active compared to the trimers, with $\mathrm{IC}_{50}$ of $2.6 \mathrm{nM}$ for both of them (Reiter et al. 2015).

Artesunate triazine hybrids (31 and $\mathbf{3 2}$ ) synthesized by Cloete et al. (2014) were active antimalarial compounds against both chloroquine-resistant (Dd2) and chloroquinesensitive (NK65) strains of $P$. falciparum. The synthesized dimer derivatives of artesunate were more active than their monomeric counterparts (Cloete et al. 2014). Among the promising compounds, one of them (32) exhibited $\mathrm{IC}_{50}$ of 0.0079 and $0.0102 \mathrm{mM}$ against NF54 and Dd2 strains of $P$. falciparum, respectively. The compound exhibited higher activity against $P$. falciparum NF54 but was less active against $P$. falciparum $\mathrm{Dd} 2$ compared to artesunate and dihydroartemisinin (Cloete et al. 2014).

\section{Beyond enhancing artesunate activities}

Malaria still poses a high health risk to the populace, especially where the occurrence of the resistant strains of the parasite is widespread in areas with poor vector control. Several treatment approaches have been mired by the complex nature of the life cycle of malaria parasite and the emergence of drugresistant species. Researchers are keen on finding a compound that will be effective and possess a novel mechanism of action different from those of existing drugs, in order to avoid resistance by the parasite. Over the years, several methods have been used to improve existing antimalarial compounds. This review has highlighted some approaches that resulted in improved antimalarial activity of artesunate, such as combination therapy, the use of synthetic matrix, synthesis of hybrid compounds, and chemical modifications of the structure of artesunate. Reported cases of resistance or reduced sensitivity have made some of these combination therapies to be withdrawn. It is believed that modifications of the chemical structure of artesunate and the synthesis of its hybrid compounds may avail us the opportunity of getting an array of new compounds which are more effective than artesunate and also possess novel mechanisms of action which can be deployed sequentially in combating the emergence of artesunateresistant strains over a long period of time. This is expected to reduce the scourge of the disease, especially in Africa where majority of malaria deaths occur.

\section{Compliance with ethical standards}

Conflict of interest The authors declare that they have no conflicts of interest.

\section{References}

Adebayo JO, Santana AE, Krettli AU (2012) Evaluation of the antiplasmodial and cytotoxicity potentials of husk fibre extracts from Cocos nucifera, a medicinal plant used in Nigeria to treat human malaria. Hum Exp Toxicol 31(3):244-249

Adebayo JO, Balogun EA, Malomo SO, Soladoye AO, Olatunji LA, Kolawole OM, Oguntoye OS, Babatunde AS, Akinola OB, Aguiar ACC, Andrade IM, Souza NB, Krettli AU (2013) Antimalarial activity of Cocos nucifera husk fibre: further studies. Evid Based Complement Alternat Med 2013:1-9

Adjuik M, Agnamey P, Babiker A, Borrmann S, Brasseur P, Cisse M, Cobelens F, Diallo S, Faucher JF, Garner P, Gikunda S, Kremsner PG, Krishna S, Lell B, Loolpapit M, Matsiegui PB, Missinou MA, Mwanza J, Ntoumi F, Olliaro P, Osimbo P, Rezbach P, Some E, Taylor WR (2002) Amodiaquine-artesunate versus amodiaquine for uncomplicated Plasmodium falciparum malaria in African children: a randomised, multicentre trial. Lancet 20 359(9315):1365-1372

Agnandji ST, Lell B, Soulanoudjingar SS et al (2015) Clinical trials partnership efficacy and safety of RTS,S/AS01 malaria vaccine with or without a booster dose in infants and children in Africa: final results of a phase 3, individually randomised, controlled trial. Lancet 386(9988):31-45

Al-Qaraghuli M, Alzahrani A, Niwasabutra K, Obeid M, Ferro V (2017) Where traditional drug discovery meets modern technology in the quest for new drugs. Ann Pharmacol Pharmaceutics 11:1061

Amolegbe SA, Hirano Y, Adebayo JO, Ademowo OG, Balogun EA, Obaleye JA, Krettli AU, Yu C, Hayami S (2018) Mesoporous silica nanocarriers encapsulated antimalarials with high therapeutic performance. Sci Rep 8:3078-3086

Anthony MP, Burrows JN, Duparc S, Moehrle JJ, Wells TN (2012) The global pipeline of new medicines for the control and elimination of malaria. Malar J 11:316

Baird JK, Hoffman SL (2004) Primaquine therapy for malaria. Clin Infect Dis 39:1336-1345

Barnes KI, Mwenechanya J, Tembo M, McIlleron H, Folb PI, Ribeiro I, Little F, Gomes M, Molyneux ME (2004) Efficacy of rectal artesunate compared with parenteral quinine in initial treatment of moderately severe malaria in African children and adults: a randomised study. Lancet 363:1598-1605

Barnett DS, Guy RK (2014) Antimalarials in development in 2014. Chem Rev 114:11221-11241

Batty KT, Ilett KF, Davis T (1996) Chemical stability of artesunate injection and proposal for its administration by intravenous infusion. $\mathrm{J}$ Pharm Pharmacol 48:22-26

Bhisutthibhan J, Meshnick SR (2001) Immunoprecipitation of $[3 \mathrm{H}]$ dihydroartemisinin translationally controlled tumor protein (TCTP) adducts from Plasmodium falciparum-infected erythrocytes by using anti-TCTP antibodies. Antimicrob Agents Chemother 45(8):2397-2399

Biot C (2004) Ferroquine: a new weapon in the fight against malaria. Curr Med Chem Anti Infect Agents 3:135-147

Biot C, Taramelli D, Forfar-Bares I, Maciejewski LA, Boyce M, Nowogrocki G, Brocard JS, Basilico N, Olliaro P, Egan TJ (2005) Insights into the mechanism of action of ferroquine relationship between physicochemical properties and antiplasmodial activity. Mol Pharmaceutics 2:185-193

Boechat N, Souza MVN, Valverde AL, Krettli AU (2014) Compounds derived from artesunate, preparation process, pharmaceutical composition and use of the respective medicine. US Patent 8,071,777 B2

Butler AR, Wu YL (1992) Artemisinin (Qinghaosu): a new type of antimalarial drug. Chem Soc Rev 21(2):85-90

Campos SB, Rouch LHK, Seguro AC (2001) Effects of sodium artesunate, a new antimalarial drug, on renal function. Kidney Int 59:1044-1051 
Chadha R, Gupta S, Shukla G, Jain DVS, Pissurlenkar RRS, Coutinho EC (2011) Interaction of artesunate with $\beta$-cyclodextrin: characterization, thermodynamic parameters, molecular modeling, effect of PEG on complexation and antimalarial activity. Results Pharma Sci $1: 38-48$

Chadha R, Saini A, Arora P, Bhandari S (2012) Pharmaceutical co-crystals: a novel approach for oral bioavailability enhancement of drugs. Crit Rev Ther Drug Carrier Syst 29(3):183-218

Chaturvedi D (2011) Sesquiterpene lactones: structural diversity and their biological activities. In: Tiwari VK, Mishra BB (eds) Opportunity, challenge and scope of natural products in medicinal chemistry. Research Signpost, Kerala, pp 313-334

Chekem L, Wierucki S (2006) Extraction de l'artémisinine et synthèse de ses dérivés artésunate et artéméther [Extraction of artemisinin and synthesis of its derivates artesunate and artemether]. Med Trop (Mars) 66(6):602-605

Cimanga K, Bruyne TD, Pieters L, Vlietinck AJ, Turger CA (1997) In vitro and in vivo antiplasmodial activity of cryptolepine and related alkaloids from Cryptolepis sanguinolenta. J Nat Prod 60:688691

Cloete TT, Kock C, Smith PJ, N'da DD (2014) Synthesis, in vitro antiplasmodial activity and cytotoxicity of a series of artemisinin etriazine hybrids and hybrid-dimers. Eur J Med Chem 76:470-481

Coertzen D, Reader J, van der Watt M, Nondaba SH, Gibhard L, Wiesner L, Smith P, D'Alessandro S, Taramelli D, Wong HN, du Preez JL, Wu RWK, Birkholtz LM, Haynes RK (2018) Artemisone and artemiside are potent panreactive antimalarial agents that also synergize redox imbalance in Plasmodium falciparum transmissible gametocyte stages. Antimicrob Agents Chemother 62(8):e02214 e02217

Conyers RC, Mazzone JR, Tripathi AK, Sullivan DJ, Posner GH (2015) Antimalarial chemotherapy: orally curative artemisinin-derived trioxane dimer esters. Bioorg Med Chem Lett 25:245-248

Croft SL, Duparc S, Arbe-Barnes SJ, Craft JC, Shin CS, Fleckenstein L, Borghini-Fuhrer I, Rim HJ (2012) Review of pyronaridine antimalarial properties and product characteristics. Malarial J 11:270 298

Cuong BT, Binh VQ, DaiB DDN, Lovell CM, Rickman KH, Edstein MD (2006) Does gender, food or grapefruit juice alter the pharmacokinetics of primaquine in healthy subjects? Br J Clin Pharmacol 61: 682-689

Dahl EL, Shock JL, Shenai BR, Gut J, DeRisi JL, Rosenthal PJ (2006) Tetracyclines specifically target the apicoplast of the malaria parasite Plasmodium falciparum. Antimicrob Agents Chemother 50(9): 3124-3131

Daum RS (2007) Clinical practice skin and soft-tissue infections caused by methicillin-resistant Staphylococcus aureus. N Engl J Med 357(4):380-390

Dharia NV, Plouffe D, Bopp SE, González-Páez GE, Lucas C, Salas C, Soberon V, Bursulaya B, Kochel TJ, Bacon DJ, Winzeler EA (2010) Genome scanning of Amazonian Plasmodium falciparum shows subtelomeric instability and clindamycin-resistant parasites. Genome Res 20(11):1534-1544

Douroumis D, Fahr A (2013) Drug delivery strategies for poorly watersoluble drugs. Advances in pharmaceutical technology. Wiley 6791:373-400

Drew MGB, Metcalfe J, Dascombe MJ, Ismail FMD (2006) Reactions of artemisinin and arteether with acid: implications for stability and mode of antimalarial action. J Med Chem 49(20):6065-6073

Drew MGB, Metcalfe J, Dascombe MJ, Ismail FMD (2007) De novo identification and stability of the artemisinin pharmacophore: studies of the reductive decomposition of deoxyartemisinins and deoxyarteethers and the implications for the mode of antimalarial action. J Mol Struct Theochem 823:34-46

Eckstein-Ludwig U, Webb RJ, Van Goethem ID, East JM, Lee AG, Kimura M, O’Neill PM, Bray PG, Ward SA, Krishna S (2003)
Artemisinins target the SERCA of Plasmodium falciparum. Nature 424:957-961

Edstein MD, Veenendaal JR (1987) Chlorproguanil and chlorcycloguanil concentrations in human plasma and urine after Lapudrine administration. Trans R Soc Trop Med Hyg 81(1):136-139

Edwards G, McGrath CS, Ward SA, Supanaranond W, Pukrittayakamee S, Davis TM, White NJ (1993) Interactions among primaquine, malaria infection and other antimalarials in Thai subjects. Br J Clin Pharmacol 35:193-198

Fahr A, Liu X (2007) Drug delivery strategies for poorly water-soluble drugs. Expert Opin Drug Deliv 4(4):403-416

Fröhlich T, Hahn F, Belmudes L, Leidenberger M, Friedrich O, Kappes B, Couté Y, Marschall M, Tsogoeva SB (2018) Synthesis of artemisinin-derived dimers, trimers and dendrimers: investigation of their antimalarial and antiviral activities including putative mechanisms of action. Chemistry 24(32):8103-8113

Gabriëls M, Plaizier-Vercammen J (2003) Physical and chemical evaluation of liposomes, containing artesunate. J Pharm Biomed Anal 31: $655-667$

Galappaththy GNL, Tharyan P, Kirubakaran R (2013) Primaquine for preventing relapse in people with Plasmodium vivax malaria treated with chloroquine. Cochrane Database Syst Rev 10:CD004389

Gandra S, Barter DM, Laxminarayan R (2014) Economic burden of antibiotic resistance: how much do we really know? Clin Microbiol Infect 20(10):973-980

Gautam A, Ahmedm T, BatraV PJ (2009) Pharmacokinetics and pharmacodynamics of endoperoxide antimalarials. Curr Drug Metab 10: 289-306

German PI, Aweeka FT (2008) Clinical pharmacology of artemisininbased combination therapies. Clin Pharmacokinet 47(2):91-102

Ginsburg H, Famin O, Zhang JM, Krugliak M (1998) Inhibition of glutathione-dependent degradation of heme by chloroquine and amodiaquine as a possible basis for their antimalarial mode of action. Biochem Pharmacol 56:1305-1313

Gogtay NJ, KadamVS KDR, KanburA KKD, Kshirsagar NA (2000) Probable resistance to parenteral artemether in Plasmodium falciparum: case reports from Mumbai (Bombay), India. Ann Trop Med Parasitol 94:519-520

Graves PM, Gelband H, Garner P (2012) Primaquine for reducing Plasmodium falciparum transmission. Cochrane Database Syst Rev 9:CD008152

Gregoriadis G (1976) The carrier potential of liposomes in biology and medicine (second of two parts). N Engl J Med 295:765-770

Griffith KS, Lewis LS, Mali S, Parise ME (2007) Treatment of malaria in the United States: a systematic review. J Am Med Assoc 297(20): 2264-2277

Harin AK, John R, Kerry L, Elizah D, Juliana H, Madhu P, Gregory MC, Kenneth FI, Timothy MED (2006) Artesunate suppositories versus intramuscular artemether for treatment of severe malaria in children in Papua New Guinea. Antimicrob Agents Chemother 50(3):968974

Harsha K, Siddhesh J, Krishnapriya M, Mrunal A, Supriya S (2020) Investigation of pre-clinical pharmacokinetic parameters of atovaquone nanosuspension prepared using $\mathrm{pH}$ based precipitation method and its pharmacodynamic properties in a novel artemisinin combination. J Glob Antimicrob Resist 22:248-256. https://doi.org/ 10.1016/j.jgar.2020.02.018

Haynes RK (2006) From artemisinin to new artemisinin antimalarials: biosynthesis, extraction, old and new derivatives, stereochemistry and medicinal chemistry requirements. Curr Top Med Chem 6(5): 509-537

Haynes RK, Cheu K-W, N'Da D, Coghi P, Monti D (2013) Considerations on the mechanism of action of artemisinin antimalarials: part 1 - the 'carbon radical' and 'heme' hypotheses. Infect Disord Drug Targets 13(4):217-277 
Held J, Jeyaraj S, Kreidenweiss A (2015) Antimalarial compounds in phase II clinical development. Expert Opin Investig Drugs 24(3): 363-382

Hunt NH, Stocker R (1990) Oxidative stress and the redox status of malaria-infected erythrocytes. Blood Cells 16(2-3):499-530

Ilett KF, Ethell BT, Maggs JL, Davis TM, Batty KT, Burchell B, Binh TQ, Thule TA, Hung NC, Pirmohamed M, Park BK, Edwards G (2002) Glucuronidation of dihydroartemisinin in vivo and by human liver microsomes and expressed UDP-glucuronosyltransferases. Drug Metab Dispos 30(9):1005-1012

Institute of Parasitic Diseases Chinese Academy of Medical Sciences (1980) Experimental studies on chemotherapeutic effects and toxicities of a new antimalarial drug 7351 (author's transl). Yao Xue Xue Bao 15:630-632

Kannan R, Sahal D, Chauhan VS (2002) Heme-artemisinin adducts are crucial mediators of the ability of artemisinin to inhibit heme polymerization. Chem Biol 9:321-332

Kim J, Yang J, Lee J, Choi G, Park D, Jo M, Choi S, Choy J (2015) 2D inorganic-antimalarial drug-polymer hybrid with $\mathrm{pH}$ responsive solubility. Chem Asian J 10:2264-2271

Kirby GC, Paine A, Warhurst DC, Noamese BK, Phillipson JD (1995) In vitro and in vivo antimalarial activity of cryptolepine, a plantderived indoloquinoline. Phytother Res 9:359-363

Krishna S, White NJ (1996) Pharmacokinetics of quinine, chloroquine and amodiaquine: clinical implications. Clin Pharmacokinet 30(4): 263-299

Krishna S, Uhlemann AC, Haynes RK (2004) Artemisinins: mechanisms of action and potential for resistance. Drug Resist Updat 7(4-5): 233-244

Lacaze C, Kauss T, Kiechel JR, Caminiti A, Fawaz F, Terrassin L, Cuart S, Grislain L, Navaratnam V, Ghezzoul B, Gaudin K, White NJ, Olliaro P, Millet P (2011) The initial pharmaceutical development of an artesunate/amodiaquine oral formulation for the treatment of malaria: a public-private partnership. Malar J 10:142

Lee JH, Kim HR, Lee JH, Lee SK, Chun Y, Han SO, Yoo HY, Park C, Kim SW (2019) Enhanced in-vitro hemozoin polymerization by optimized process using histidine-rich protein II (HRPII). Polymers 11:1162-1175

Lell B, Kremsner PG (2002) Clindamycin as an antimalarial drug: review of clinical trials. Antimicrob Agents Chemother 46(8):2315-2320

Li GD, Liu SQ, Ye XY, Qu FY (1995) Detection of 54-kDa protein overexpressed by chloroquine-resistant Plasmodium berghei ANKA strain in pyronaridine-resistant $P$. berghei ANKA strain. Zhongguo Yao Li Xue Bao 16:17-20

Li Q, Peggins JO, Fleckenstein LL, Masonic K, Heiffer MH, Brewer TG (1998) The pharmacokinetics and bioavailability of dihydroartemisinin, meether, artemether, artesunic acid and artelinic acid in rats. J Pharm Pharmacol 50:173-182

Looareesuwan S, Kyle DE, Viravan C, Vanijanonta S, Wilairatana P, Wernsdorfer WH (1996) Clinical study of pyronaridine for the treatment of acute uncomplicated falciparum malaria in Thailand. Am J Trop Med Hyg 54:205-209

Luxemburger C, Brockman A, Silamut K, Nosten F, van Vugt M, Gimenez F, Chongsuphajaisiddhi T, White NJ (1998) Two patients with falciparum malaria and poor in vivo responses to artesunate. Trans R Soc Trop Med Hyg 92:668-669

Majori G (2004) Combined antimalarial therapy using artemisinin. Parasitologia 46:85-87

Makino K, Shibata A (2006) Surface properties of liposomes depending on their composition. In: Leitmannova Liu A (ed) Advances in planar lipid bilayers and liposomes. Elsevier, Amsterdam, pp 49-77

Marquiño W, Ylquimiche L, Hermenegildo Y, Palacios AM, Falconí E, Cabezas C, Arróspide N, Gutierrez S, Ruebush TK (2005) Efficacy and tolerability of artesunate plus sulfadoxine-pyrimethamine and sulfadoxine-pyrimethamine alone for the treatment of uncomplicated Plasmodium falciparum malaria in Peru. Am J Trop Med Hyg 72(5):568-572

McGready R, Keon NK, Villegas L, White NJ, Looareesuwan S, Nosten F (2003) Artesunate-atovaquone-proguanil rescue treatment of multidrug-resistant Plasmodium falciparum malaria in pregnancy: a preliminary report. Trans R Soc Trop Med Hyg 97(5):592-594

Meunier B (2007) Hybrid molecules with a dual mode of action: dream or reality? Acc Chem Res 41:69

Mohammadi S, Jafari B, Asgharian P, Martorell M, Sharifi-Rad J (2020) Medicinal plants used in the treatment of malaria: a key emphasis to Artemisia, Cinchona, Cryptolepis, and Tabebuia genera. Phytother Res 34(7):1556-1569

Morris CA, Duparc S, Borghini-Fuhrer I, Jung D, Shin C, Fleckenstein L (2011) Review of the clinical pharmacokinetics of artesunate and its active metabolite dihydroartemisinin following intravenous, intramuscular, oral or rectal administration. Malar J 10:263

Muder AH, Sunderland VB (2014) Effect of hydroxypropyl- $\beta$ cyclodextrin complexation on the aqueous solubility and stability of artesunate. Int J Pharm Pharm Sci 6(7):95-98

Nigam M, Atanassova M, Mishra AP, Pezzani R, Devkota HP, Plygun S, Salehi B, Setzer WN, Sharifi-Rad J (2019) Bioactive compounds and health benefits of Artemisia species. Nat Prod Commun 14(7): $1-17$

Noedl H, Se Y, Schaecher K, Smith BL, Socheat D, Fukuda MM (2008) Evidence of artemisinin-resistant malaria in western Cambodia. $\mathrm{N}$ Engl J Med 359(24):2619-2620

Nosten F, Imvithaya S, Vincenti M, Lebihan G, Hausler B, White NJ (1987) Malaria on the Thai-Burmese border: treatment of $5182 \mathrm{pa}-$ tients with mefloquine sulfadoxine-pyrimethamine. Bull World Health Organ 65:891-896

Nosten F, ter Kuile F, Chongsuphajaisiddhi T, Luxemburger C, Webster HK, Edstein M, Phaipun L, Thew KL, White NJ (1991) Mefloquine-resistant falciparum malaria on the Thai-Burmese border. Lancet 337:1140-1143

Nosten F, Phillips-Howard PA, Ter Kuile FO (2012) Other 4methanolquinolines, amyl alcohols and phentathrenes: mefloquine, lumefantrine and halofantrine. In: Staines HM, Krishna S (eds) Treatment and prevention of malaria antimalarial drug chemistry, action and use. Springer, London, pp 95-112

Nzila A (2012) Antifolates: pyrimethamine, proguanil, sulphadoxine and dapsone. In: Staines HM, Krishna S (eds) Treatment and prevention of malaria antimalarial drug chemistry, action and use. Springer, London, pp 113-126

Obeid MA, Khadra I, Mullen AB, Tate RJ, Ferro VA (2017a) The effects of hydration media on the characteristics of non-ionic surfactant vesicles (NISV) prepared by microfluidics. Int J Pharm 516:52-60

Obeid MA, Elburi A, Young LC, Mullen AB, Tate RJ, Ferro VA (2017b) Formulation of nonionic surfactant vesicles (NISV) prepared by microfluidics for therapeutic delivery of siRNA into cancer cells. Mol Pharm 14:2450-2458

Obonyo CO, Ochieng F, Taylor WR, Ochola SA, Mugitu K, Olliaro P, ter Kuile F, Oloo AJ (2003) Artesunate plus sulfadoxinepyrimethamine for uncomplicated malaria in Kenyan children: a randomized, double-blind, placebo-controlled trial. Trans R Soc Trop Med Hyg 97(5):585-591

Oduola AM, Sowunmi A, Milhous WK, Kyle DE, Martin RK, Walker O, Salako LA (1992) Innate resistance to new antimalarial drugs in Plasmodium falciparum from Nigeria. Trans R Soc Trop Med Hyg 86:123-126

Ouji M, Augereau JM, Paloque L, Benoit-Vical F (2018) Plasmodium falciparum resistance to artemisinin-based combination therapies: a sword of Damocles in the path toward malaria elimination. Parasite 25:24

Paik IH, Xie S, Shapiro TA, Labonte T, Sarjeant AAN, Baege AC, Posner GH (2006) Second generation, orally active, antimalarial, 
artemisinin-derived trioxane dimers with high stability, efficacy, and anticancer activity. J Med Chem 49:2731-2734

Palmer KJ, Holliday SM, Brogden RN (1993) Mefloquine a review of its antimalarial activity, pharmacokinetic properties and therapeutic efficacy. Drugs 45:430-475

Pandey AV, Tekwani BL, Singh RL, Chauhan VS (1999) Artemisinin, an endoperoxide antimalarial, disrupts the hemoglobin catabolism and heme detoxification systems in malarial parasite. J Biol Chem 27: 19383-19388

Paulo A, Gomes ET, Steele J, Warhurst DC, Houghton PJ (2000) Antiplasmodial activity of Cryptolepis sanguinolenta alkaloids from leaves and roots. Planta Med 66:30-34

Pearce AN, Kaiser M, Copp BR (2017) Synthesis and antimalarial evaluation of artesunate-polyamine and trioxolanepolyamine conjugates. Eur J Med Chem 40:595-603

Peter IT, Anatoli KK (1998) The current global malaria situation: malaria parasite biology, pathogenesis and protection. ASM Press, Washington, pp 11-22

Piyaphanee W, Krudsood S, Tangpukdee N, Thanachartwet W, Silachamroon U, Phophak N, Duangdee C, Haoharn O, Faithong S, Wilairatana P, Leowattana W, Looareesuwan S (2006) Emergence and clearance of gametocytes in uncomplicated Plasmodium falciparum malaria. Am J Trop Med Hyg 74:432-435

Poravuth Y, Socheat D, Rueangweerayut R, Uthaisin C, Pyae Phyo A, Valecha N, Rao BH, Tjitra E, Purnama A, Borghini-Fuhrer I, Duparc S, Shin CS, Fleckenstein L (2011) Pyronaridine-artesunate versus chloroquine in patients with acute Plasmodium vivax malaria: a randomised, double-blind, non-inferiority trial. PLoS One 6: e14501

Posner GH, O'Neill PM (2004) Knowledge of the proposed chemical mechanism of action and cytochrome P450 metabolism of antimalarial trioxanes like artemisinin allows rational design of new antimalarial peroxides. Acc Chem Res 37(6):397-404

Pukrittayakamee S, Chantra A, Simpson JA, Vanijanonta S, Clemens R, Looareesuwan S, White NJ (2000) Therapeutic responses to different antimalarial drugs in vivax malaria. Antimicrob Agents Chemother 44:1680-1685

Pukrittayakamee S, Imwong M, Singhasivanon P, Stepniewska K, Day NJ, White NJ (2008) Effects of different antimalarial drugs on gametocyte carriage in P. vivax malaria. Am J Trop Med Hyg 79:378384

Randrianarivelojosia M, Raharimalala LA, Randrianasolo L, Ratsimbasoa A, Rason MA, Ariey F, Jambou R (2001) Madagascan isolates of Plasmodium falciparum showing low sensitivity to artemether in vitro. Ann Trop Med Parasitol 95:237-243

Rappuoli R, Aderem A (2011) A 2020 vision for vaccines against HIV, tuberculosis and malaria. Nature 473:463-469

Reiter C, Frohlich L, Gruber L, Hutterer C, Marschall M, Voigtländer C, Friedrich O, Kappes B, Efferth T, Tsogoeva SB (2015) Highly potent artemisinin-derived dimers and trimers: synthesis and evaluation of their antimalarial, antileukemia and antiviral activities. Bioorg Med Chem 23:5452-5458

Rueangweerayut R, Phyo A, Uthaisin C, Poravuth Y, Binh T, Tinto H, Pénali L, Valecha N, Tien N, Abdulla S, Borghini-Fuhrer I, Duparc S, Shin CS, Fleckenstein L (2012) Pyronaridine-artesunate versus mefloquine plus artesunate for malaria. N Engl J Med 366:12981309

Sachs J, Malaney P (2002) The economic and social burden of malaria. Nature 415:680-685

Sahr F, Willoughby VR, Gbakima AA, Bockarie MJ (2001) Apparent drug failure following artesunate treatment of Plasmodium falciparum malaria in Freetown, Sierra Leone: four case reports. Ann Trop Med Parasitol 95:445-449

Schrader FC, Marlene Barho M, Steiner I, Ortmann R, Schlitzer M (2012) The antimalarial pipeline - an update. Int J Med Microbiol 302:165171
Setyawan D, Wardhana NK, Sari R (2015) Solubility, dissolution test and antimalarial activity of artesunate nicotinamide co-crystal prepared by solvent evaporation and slurry methods. Asian J Pharm Clin Res 8(2):164-166

Singh K, Kaur H, Smith P, de Kock C, Chibale K, Balzarini J (2014) Quinoline-pyrimidine hybrids: synthesis, antiplasmodial activity, SAR, and mode of action studies. J Med Chem 57:435-448

Steyn JD, Wiesner L, du Plessis LH, Grobler AF, Smith PJ, Chan WC, Haynes RK, Kotzé AF (2011) Absorption of the novel artemisinin derivatives artemisone and artemiside: potential application of Pheroid technology. Int J Pharm 414:260-266

Tahar R, Almelli T, Debue C, Ngane VF, Allico JD, Youdom SW, Basco LK (2014) Randomized trial of artesunate-amodiaquine, atovaquone-proguanil, and artesunate-atovaquone-proguanil for the treatment of uncomplicated falciparum malaria in children. $\mathrm{J}$ Infect Dis 210(12): 1962-1971

Taylor-Robinson AW, Looker M (1998) Sensitivity of malaria parasites to nitric oxide at low oxygen tensions. Lancet 351:30

Teixeira C, Vale N, Pérez B, Gomes A, Gomes JRB, Gomes P (2014) "Recycling" classical drugs for malaria. Chem Rev 114:1164-1220

Teja-Isavadharm P, Watt G, Eamsila C, Jongsakul K, Li Q, Keeratithakul D, Sirisopana N, Luesutthiviboon L, Brewer TG, Kyle DE (2001) Comparative pharmacokinetics and effect kinetics of orally administered artesunate in healthy volunteers and patients with uncomplicated falciparum malaria. Am J Trop Med Hyg 65(6):717-721

Tenson T, Lovmar M, Ehrenberg M (2003) The mechanism of action of macrolides, lincosamides and streptogramin $\mathrm{B}$ reveals the nascent peptide exit path in the ribosome. J Mol Biol 330:1005-1014

ter Kuile FO, Nosten F, Luxemburger C, Kyle D, Teja-Isavatharm P, Phaipun L, Price R, Chongsuphajaisiddhi T, White NJ (1995) Mefloquine treatment of acute falciparum malaria: a prospective study of non-serious adverse effects in 3673 patients. Bull World Health Organisation 75:631-642

Thu AM, Phyo AP, Landier J, Parker DM, Nosten FH (2017) Combating multidrug-resistant Plasmodium falciparum malaria. FEBS J 284(16):2569-2578

van Vugt M, Edstein MD, Proux S, Lay K, Ooh M, Looareesuwan S, White NJ, Nosten F (1999) Absence of an interaction between artesunate and atovaquone-proguanil. Eur J Clin Pharmacol 55(6): 469-474

van Vugt M, Leonardi E, Phaipun L, Slight T, Thway KL, McGready R, Brockman A, Villegas L, Looareesuwan S, White NJ, Nosten F (2002) Treatment of uncomplicated multidrug-resistant falciparum malaria with artesunate-atovaquone-proguanil. Clin Infect Dis 35(12): 1498-1504

Varotti F, Botelho ACC, Andrade AA, de Paula RC, Fagundes EMS, Valverde A, Mayer LMU, Mendonça JS, Marcus VN, Boechat N, Krettli AU (2008) Synthesis, antimalarial activity, and intracellular targets of MEFAS, a new hybrid compound derived from mefloquine and artesunate. Antimicrob Agents Chemother 52(11):38683874

Wang N, Wicht KJ, Shaban E, Ngoc TA, Wang M, Hayashi I, Hossain MI, Takemasa Y, Kaiser M, El Sayed IE, Egan TJ, Inokuchi T (2014) Synthesis, $\beta$-haematin inhibition, and in vitro antimalarial testing of isocryptolepine analogues: SAR study of indolo[3,2c]quinolines with various substituents at C2, C6, and N11. Bioorg Med Chem 22(9):2629-2642

Wani WA, Jameel E, Baig U, Mumtazuddin S, Hun LT (2015) Ferroquine and its derivatives: new generation of antimalarial agents. Eur J Med Chem 101:534-551

Waters NC, Edstein MD (2012) In: Staines HM, Krishna S (eds) Treatment and prevention of malaria, antimalarial drug: chemistry, action and use. Springer, London, pp 69-94

White NJ (1998) Preventing antimalarial drug resistance through combinations. Drug Resist Updat 1:3-9 
White NJ (1999a) Delaying antimalarial drug resistance with combination chemotherapy. Parasitologia 41:301-308

White NJ (1999b) Antimalarial drug resistance and combination chemotherapy. Phil Trans R Soc Lond B 354:739-749

White NJ (2008) Qinghaosu (artemisinin): the price of success. Science 320:330-334

White NJ, Olliaro PL (1996) Strategies for the prevention of anti-malarial drug resistance: rationale for combination chemotherapy for malaria. Parasitol Today 12:399-401

Winstanley PA, Watkins WM, Muhia D, Szwandt S, Amukoye E, Marsh K (1997) Chlorproguanil-dapsone for uncomplicated falciparum malaria in young children: pharmacokinetics and therapeutic range. Trans R Soc Trop Med Hyg 91:322-327

Wiseman V, Kim M, Mutabingwa TK, Whitty CJ (2006) Costeffectiveness study of three antimalarial drug combinations in Tanzania. PLoS Med 3:373

Wojnarski M, Lon C, Vanachayangkul P, Gosi P, Sok S, Rachmat A, Harrison D, Berjohn CM, Spring M, Chaoratanakawee S, Ittiverakul M (2019) Atovaquone-proguanil in combination with artesunate to treat multidrug-resistant $P$. falciparum malaria in Cambodia: an open-label randomized trial. In: Open forum infectious diseases, vol 6, 9. Oxford University Press, Oxford, p ofz314

World Health Organization (2001) Antimalarial drug combination therapy report of a WHO technical consultation. Roll Back Malaria/ World Health Organization, Geneva

World Health Organization (2006) WHO calls for an immediate halt to provision of single-drug artemisinin malaria pills. World Health Organization, Washington, p 2006

World Health Organization (2007) WHO Resolution WHA6018 Malaria, including proposal for establishment of World Malaria Day In: Sixtieth World Health Assembly, Geneva, Resolutions and decisions, annexes Geneva: World Health Organization; 2007 (WHA60/2007/REC/1)
World Health Organization (2010) WHO guidelines for the treatment of malaria, 2nd edn. World Health Organization, Geneva

World Health Organization (2012) Malaria Policy Advisory Committee Meeting WHO Evidence Review Group: the safety and effectiveness of single dose primaquine as a $P$. falciparum gametocytocide. World Health Organization, Geneva

World Health Organization (2015) WHO guidelines for the treatment of malaria, 3rd edition, https://extranet.who.int/iris/restricted/bitstream/ handle/10665/162441/9789241549127_eng.pdf. Accessed 3 Jul 2020

World Health Organization (2017) World malaria report 2017. World Health Organization, Geneva

World Health Organization (2019) World malaria report 2019. World Health Organization, Geneva

World Health Organization (2020). Q\&A on the malaria vaccine implementation programme (MVIP). Retrieved from https://www.who. int/malaria/media/malaria-vaccine-implementation-qa/en/ (accessed on 30 Mar 2020)

Wu LJ (1988) Effects of large doses of pyronaridine and chloroquine on the ultrastructure of the erythrocytic stages of pyronaridine-resistant line of Plasmodium berghei (in Chinese). Zhongguo Yao Li Xue Bao 9:87-89

Ye XY, Shao BR (1990) Tissue schizontocidal action and acute toxicity of trifluoroacetyl primaquine in Chinese. Zhongguo Yao Li Xue Bao 11:359-362

Zhang X, Liu J, Qiao H, Liu H, Ni J, Zhang W, Shi Y (2009) Formulation optimization of dihydroartemisinin nanostructured lipid carrier using response surface methodology. Powder Technol 197:120-128

Zuidema J, Hilbers-Modderman ESM, Merkus FWHM (1986) Clinical pharmacokinetics of dapsone. Clin Pharmacokinet 11(4):299-315

Publisher's note Springer Nature remains neutral with regard to jurisdictional claims in published maps and institutional affiliations. 